\title{
Population dynamics and climate change: A challenging frontier for the intrepid demographer
}

\author{
Adrian C. Hayes*
}

I am grateful to the editors for inviting me to contribute to the Demographic Debate Section of this Vienna Yearbook of Population Research Special Issue on Demographic Differential Vulnerability to Natural Disasters in the Context of Climate Change. They have asked me to address the question: Why are so few demographers working on climate change? This begs the question of what they might mean by 'so few', but I will return to that issue in a moment. To begin with I want to outline three demanding challenges that any intrepid demographer-or any other social scientist for that matter-faces if she wants to work on anthropogenic climate change with the aim of making a significant contribution to our scientific understanding of its causes and consequences.

First, the Earth's climate system is extremely complex, and climate science brings together theories, data, and methodologies from a wide array of the physical sciences, including physics, chemistry, meteorology, biology, ecology, and geology. No single researcher can master all of these fields of inquiry comprehensively, but anyone who wants to understand how human populations are altering the climate will need a firm grasp of the climate system's basic dynamics. This means acquiring sufficient knowledge of the component parts of the system, of their respective physical properties, and of how these properties interact. In addition, it is important to understand how the whole system is driven by solar energy. Comprehending climate science can thus represent a steep learning curve for a demographer, not least because demographers (like most social scientists) are trained to focus on the socially meaningful aspects of populations, not on their physical properties. But it is precisely the physical nature of what populations do that our intrepid demographer will need to embrace in her research if she is to improve our understanding of how humans are changing the climate. It may be worth noting in passing that many popular accounts of climate change written for the proverbial layperson will not take

*Adrian C. Hayes, School of Demography, Australian National University, Canberra ACT 0200, Australia

Email: adrian.hayes@anu.edu.au 
our demographer very far in developing her understanding of the basics of climate science, as they can be misleading: for example, they may explain the so-called greenhouse effect, but without clarifying why this term is in fact a gross misnomer, as the British physicist R.W. Wood demonstrated experimentally in 1909 that the reason the typical garden greenhouse is hot inside is not primarily because of the radiative properties of the glass!

Second, it is not enough for our intrepid demographer simply to get more physical; she will also need to find or fashion a conceptual framework capable of integrating the physical with the social. The framework used in the integrated assessment models (IAM) of the IPCC will not satisfy many demographers (or other social scientists) because it gives little attention to basic social facts like agency, the heterogeneity of populations, inequality, vested interests, and conflict. These gaps are understandable given the preponderance of physical scientists in the work of the IPCC: they have made heroic efforts to master the complexity of the climate system, but have no mandate or inclination to recognize and master the complexity of human populations and societies. Our intrepid demographer will need a framework that can help rectify this imbalance.

A number of conceptual frameworks purporting to integrate the human and the natural have found their way into population and environment studies over the last 50 years. This literature can be mined to help fashion a suitable framework for population-climate research. The limitation of many population-environment perspectives is, however, that they identify population-environment interactions in terms of broad associations (for example, between human consumption of goods and services on the one hand and pollution and the depletion of natural resources on the other), without uncovering exactly what happens at the interface of these actions (by, for example, giving a more calibrated assessment of the environmental consequences of discrete choices). When it comes to fashioning a more satisfactory integration framework, my money is on recent advances in socialecological approaches that embrace population, society, the natural environment, and the built environment (Hummel et al. 2009). Each of these components has embedded within it a distinct kind of resource or form of capital-human, social, natural, or physical - that is essential for human action. In this perspective, the basic story of population-environment interactions is about how these four forms of capital are produced, exchanged, and consumed in social-ecological systems (SESs). In the case of anthropogenic climate change, our demographer will need to consider SESs across all scales, from the individual household to global society.

The third major challenge is clarifying social values and their role in formulating the problem. Interest in anthropogenic climate change is growing around the world, not because of a rise in scientific curiosity, but because it poses an existential threat. Climate change is a very special and increasingly urgent social problem. However, if climate change is to be recast as a social problem, then researchers need to be clear and explicit about which and whose social values need to be taken into account and protected, and under what circumstances. Is the problem essentially a question of protecting human lives, livelihoods, lifestyles, or standards of living? 
How do we weigh the interests of those currently living against the interests of future generations? And how do biodiversity and the health of ecosystems fit into the equation? The ethics of climate change are far from settled, but they appear to depend on much more than conventional cost-benefit analysis. Sensing the need to season the scientific consensus with some ethical reasoning, Working Group III of the IPCC invited two moral philosophers to join the team of lead authors to write chapter three of its report for the Fifth Assessment (the chapter is titled, 'Social, Economic, and Ethical Concepts and Methods'). To make a significant contribution to the policy debates surrounding climate change, our intrepid demographer will need to endogenize human values in her perspective and not focus simply on the empirical relationships between population and climate. The social problem that the global community wants to solve can only be adequately formulated and addressed with reference to human rights and values.

Having recognised the magnitude of these challenges, we can perhaps begin to understand why relatively few demographers are working on climate change. Moreover, the number of researchers is smaller in demography than in many other social sciences, and few of these researchers are trained in population and environment or in the demography of climate change. Most demographers choose subfields more firmly grounded in the discipline (and for which substantial funding is available), such as fertility (whether it is too high or too low), changing family structures, adolescence, labour force participation, the epidemiological transition, population ageing, urbanisation, and international migration. It is also worth noting that demographers are generally less inclined to rush into new fields of inquiry than some other social scientists, not because they are narrow-minded, but because they take their commitment to empirical science very seriously, and are not inclined to speculate on topics before they have adequate data. As Caldwell (1995) put it in his 1994 Borrie Lecture: "Demographers are more closely tied to the real world. They believe that most propositions - or at least important parts of them - can be quantified and that, once this is done, tests of validity can be devised. This is not always right, and it is a weakness as well as a strength, but it does prevent too many flights of fancy and it makes most demographers intelligible to others." It is therefore perfectly understandable that only a few demographers currently focus on climate change. Is this regrettable, and, if so, what can be done about it?

In 2011 the IUSSP established a new scientific panel on climate change (with a mandate to the end of 2014). The members were Susana Adamo, Wolfgang Lutz, Leiwen Jiang, and myself as chair. Our aims were to consolidate on-going research into population and climate change, and to encourage wider and deeper interest in climate change among our colleagues. The outcomes of our efforts are hard to quantify, but I believe we were largely successful. Our first international seminar, held in Canberra in November 2012, covered a wide range of issues concerning population dynamics and climate change. We concluded there is "a major window of opportunity at present for population research on climate change if we position our research vis-à-vis the new generation of climate scenarios" being used by the IPCC, specifically the so-called shared socioeconomic pathways (SSPs) (Hayes and 
Adamo 2014). The SSPs can be thought of "as hypotheses arising about the relative importance of different processes in shaping mitigation and adaptation challenges" (Hunter and O'Neill 2014). A selection of the papers presented at the first seminar were published in a special issue of Population and Environment in March 2014. Our second seminar, held in Kao Lak in April 2014, focused specifically on adaptation research, and was hosted jointly by Chulalongkorn University and the Wittgenstein Centre. This seminar built on and expanded an already well-established research program focusing on differential vulnerability to natural disasters (Butz et al. 2014). Papers from this seminar are published in this special issue of the Vienna Yearbook. I believe these two special issues provide compelling evidence of the fruitfulness of research undertaken by demographers working on climate change today, and, perhaps even more importantly, they make a credible case that many more exciting research opportunities for demographers are likely to emerge in the future. Some previous attempts by demographers to enter environmental debates ended in frustration because it was not clear what demographers had to offer besides population estimates and projections (Caldwell 1995). The papers in these two volumes demonstrate overwhelmingly that this limitation no longer applies. As long as the current momentum in population and climate change research is maintained and the three major challenges mentioned earlier are addressed, it is, I believe, likely that many more demographers will be working in this area in the future.

\section{References}

Butz, W. P., W. Lutz and J. Sendzimir (eds) 2014. Education and differential vulnerability to natural disasters. Ecology $\mathcal{E}$ Society, Special Feature.

Caldwell, J. C. 1995. The strengths and limitations of demography, and the works of W. D. Borrie. Journal of the Australian Population Association 12(1): 1-14.

Hayes, A. C. and S. B. Adamo 2014. Introduction: Understanding the links between population dynamics and climate change. Population and Environment 35(3): 225-230.

Hummel, D., A. Lux, A. de Sherbinin and S. B. Adamo 2007. Theoretical and methodological issues in the analysis of population dynamics and supply systems. PERN Background Paper. Available at www.populationenvironmentresearch.org.

Hunter, L. M. and B. C. O’Neill 2014. Enhancing engagement between the population, environment, and climate research communities: The shared socio-economic pathway process. Population and Environment 35(3): 231-242. 